\title{
A NOVEL FINITE ELEMENT METHOD FOR HEAT TRANSFER IN THE CONTINUOUS CASTER
}

\author{
YONG-HONG WU ${ }^{1}$, JAMES M. HILL ${ }^{1}$ \\ and PAUL J. FLINT ${ }^{2}$
}

(Received 16 April 1991; revised 30 May 1992)

\begin{abstract}
In the continuous casting of steel, many problems, such as surface cracks in solidified steel and breakouts of molten steel from the bottom of moulds, frequently occur in practice. It is believed that the occurrence of these problems is directly related to the events in the mould, especially the transfer of heat from the strand surface across the lubricating mould powder and its interface with the mould wall to the mould cooling-water. However, as far as the authors are aware, there is no published work dealing with heat transfer across both the lubricating layer and the interface. Generally, a parameter representing the average overall heat transfer coefficient between the strand surface and the mould cooling-water is employed, instead of including the lubricating layer, the mould wall and their interface in the computation region. The existing treatment consequently does not permit analysis of some of the more important phenomena, such as the effect of mould powder properties and interface thermal contact resistance on the solidification of steel. In this paper, a novel finite element model is developed and the heat transfer across the interface between the lubricating layer and the mould wall is simulated by introducing a new type of element, referred to as the thermal contact element. The proposed model is used to investigate the effect of various casting parameters on heat transfer from the molten steel to the cooling-water. The results indicate that the thermal contact resistance between the mould wall and the mould powder is a key factor which dominates the thickness of the solidified steel shell and the heat extraction rate from the mould wall.
\end{abstract}

\footnotetext{
'Department of Mathematics, University of Wollongong, Wollongong, N.S.W.

${ }^{2}$ B.H.P. Research, Newcastle Laboratories, Newcastle, N.S.W.

(C) Australian Mathematical Society, 1994, Serial-fee code 0334-2700/94
} 


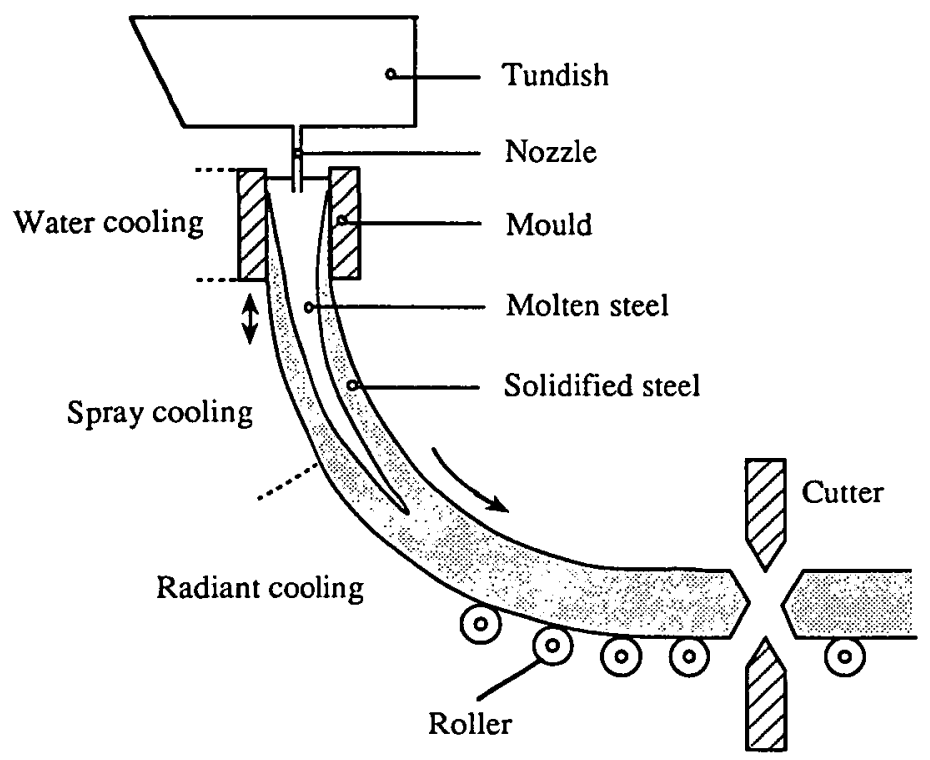

FIGURE 1. The continuous casting process.

\section{Introduction}

Since the early 1980s, the continuous casting of steel has been employed in the Australian steel-making industry. The essential features of this process are shown in Figure 1. Molten steel is fed from a tundish through a nozzle into a water-cooled mould and solidified steel is continuously extracted from the bottom of the mould at a constant casting speed $U$. The product is supported by rolls after leaving the mould, cooled down by water sprays and then subsequently cooled by radiation only. During the casting process mould powder is added at the top of the mould and the mould itself oscillates vertically to facilitate the continuous process and to prevent the steel from sticking to the mould walls. The mould powder melts and forms a lubricating layer, referred to as casting flux, in the gap between the solidified steel shell and the mould wall. As the flux moves down the mould wall it solidifies and so a layer of solidified flux forms between the liquid flux and the mould wall; the various layers formed in the mould during casting are shown in Figure 2.

In practice, many problems frequently occur in the casting process. These problems mainly include breakouts of molten steel from the bottom of the moulds ( Grill et al. [7] ), and shape defects and surface cracks ( Brimacombe et al. 


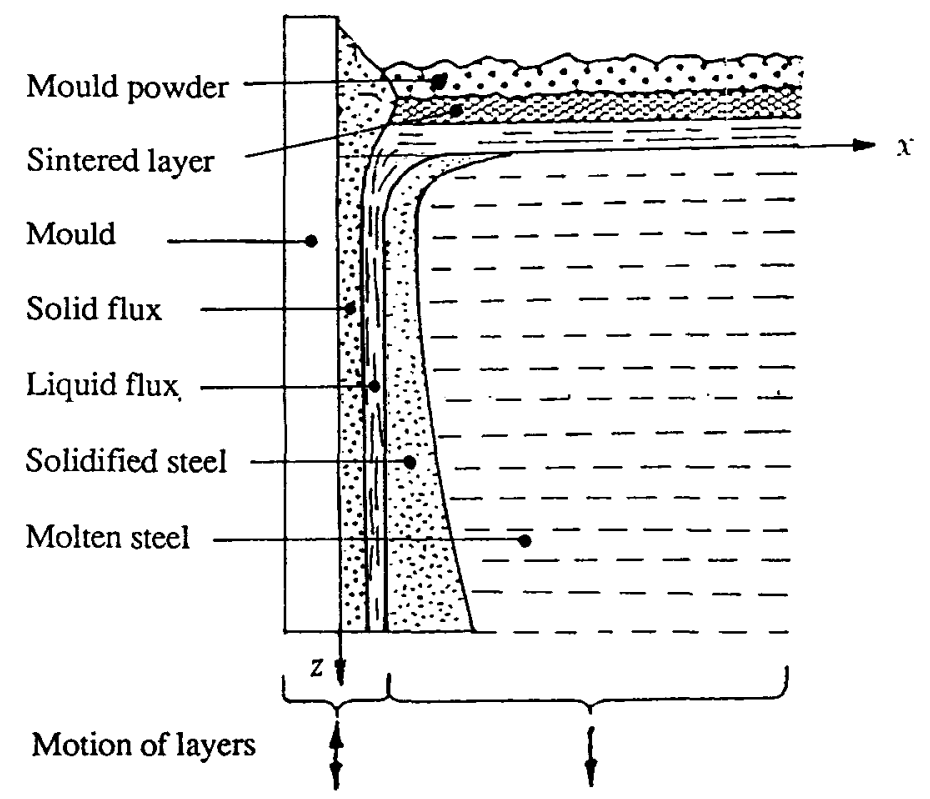

FIGURE 2. Various casting layers formed in mould.

[2], Schmidt and Fredriksson [14], and Soejima et al. [15] ). The occurrence of these problems is generally thought to be directly related to events in the mould, especially the transfer of heat from the molten steel across the solidified steel shell, the lubricating layer, the interface of the lubricating layer with the mould wall and the mould wall to the environment. With the aim of understanding the solidification process of steel during the casting process, a good deal of work on modelling heat transfer from the molten steel to the environment has been carried out and analytical studies, such as those by Bland [1], Fowkes and Woods [4] and Garcia et al. [5] have resulted in a better understanding of heat transfer in the continuous casting mould. However, existing analytical models apply only to one dimensional situations and homogeneous materials. Moreover, in deriving the various analytical solutions, a number of other assumptions are generally made to simplify the problem and consequently limit the application of these results.

Numerical models for the analysis of heat transfer in the casting mould include the boundary element model ( Hong et al. [8] ), the finite difference and the finite element model ( Gautier et al. [6], Lait et al. [9], Flint [3], Upton et al. [17], and Laitinen and Neittaanmaki [10] ). The boundary element model due 
to Hong et al. [8] can describe the effect of interface thermal resistance on heat transfer. However, the model is limited to an unrealistic case where the casting system consists of two different homogeneous layers only. On the other hand, the finite element method, as a domain discretization method, can be applied to more general cases. As far as the authors are aware, there is no published work on the finite element simulation of the transfer of heat across both the lubricating layer and its interface with the mould wall. In all the finite difference and finite element models for heat transfer in the casting mould, a parameter referred to as the average overall heat transfer coefficient between the casting surface and the mould cooling-water is used in the modelling. Consequently the computation region is limited to the surface of the casting steel and this approximation is physically unrealistic. As a result, the effect of casting parameters, such as mould powder properties, thermal contact resistance and the formation of an air gap between the mould wall and the lubricating layer, on heat transfer and solidification, cannot be actually simulated. Here we propose a new type of element, which we refer to as the thermal contact element and which we use to model the transfer of heat across the interface between two different casting layers. Since it is generally believed that most of the thermal resistance to heat transfer from the molten steel to the cooling water, is due to the thermal contact resistance between the mould wall and the flux, the development of this thermal contact element is important from a practical perspective. In this paper we incorporate this new kind of element in a finite element model.

The full problem to be solved is a three dimensional coupled heat transfersolidification-fluid flow problem and the main difficulty in solving this problem is that the position of the moving boundary (solid/liquid) is not known a-priori. Further, there exists a discontinuity in the temperature gradient across the solid/liquid interface due to the effect of latent heat, as well as a discontinuity in temperature across the interface between the lubricating layer and the mould wall. In the following section, we briefly give the governing equations and demonstrate that under certain assumptions the problem can be simplified to a two dimensional nonlinear parabolic-type initial boundary value problem. The finite element formulation for the solution of this problem is given in Section 3. Particular attention is given to the development of the thermal contact element and the iterative scheme for the solution of the discretized finite element equations. In Section 4 , the proposed model is used to investigate the effect of several casting parameters on heat transfer and solidification of steel in the casting mould. 


\section{Mathematical model}

2.1. The enthalpy formulation The basic field equations governing the steady coupled heat-transfer, solidification and fluid flow in the continuous casting process are those of three-dimensional steady-state conservation of momentum, mass and heat. These equations, under the assumption of incompressibility, can be expressed as follows:

Conservation of momentum

$$
\rho(\mathbf{u} \cdot \nabla) \mathbf{u}=-\nabla P+\mu \nabla^{2} \mathbf{u}
$$

Conservation of mass

$$
\nabla \cdot \mathbf{u}=0
$$

Conservation of heat

$$
\rho c(T)(\mathbf{u} \cdot \nabla) T=\nabla \cdot(k(T) \nabla T)+q(T),
$$

where $P$ is the liquid pressure, $T$ is the temperature, $\mu$ is the viscosity, $\mathbf{u}=(u, v, w)$ denotes the velocity vector in the Cartesian coordinate system $\mathbf{x}=(x, y, z)$ as shown in Figure 2, $\rho, c(T)$ and $k(T)$ denote density, specific heat and thermal conductivity respectively and $q(T)$ is a source term corresponding to heat being emitted or absorbed. For the phase change problem during solidification in the continuous casting of steel, $q=0$ everywhere except in the mushy region (temperature ranging from $T_{s}$ to $T_{L}$ ) where latent heat is emitted. When local freezing in a mushy zone occurs, the associated latent heat released constitutes a heat source

$$
q(T)=-\rho(\mathbf{u} \cdot \nabla) H_{L}
$$

where the latent heat $H_{L}$ in general can be expressed as a function of temperature, such as the linearly distributed function of temperature,

$$
H_{L}=f(T)=\left\{\begin{array}{cc}
L & T>T_{L}, \\
L \frac{T-T_{s}}{T_{L}-T_{s}} & T_{s} \leq T \leq T_{L} \\
0 & T<T_{s} .
\end{array}\right.
$$


Equations (2.1)-(2.5) constitute a coupled system of five equations in terms of five coordinate-dependent unknown functions $(u, v, w, P$ and $T)$ and in principle can be solved, but in practice, a great deal of computational effort is required. However, the model can be simplified by noting that:

(a) relative to heat conduction in the $x$ and $y$ directions, conduction in the withdrawal ( $z$ ) direction is normally small and can be neglected (Bland [1]);

(b) in both the solidified steel shell and the mould flux layer, the velocity components in the $x$ and $y$ directions are approximately equal to zero and hence the convective heat transfer in $x$ and $y$ directions for these regions can be neglected;

(c) the transfer of heat by convection in the liquid pool can be considered using an effective thermal conductivity reported by Lait et al. [9] to be about seven times greater than the liquid thermal conductivity;

(d) the casting steel is withdrawn from the bottom of the mould continuously and hence the downward velocity component within the computational region is assumed to be equal to the constant casting speed $U$.

On using the above simplifications, the temperature field can be solved from the single equation (2.3), which reduces to

$$
\rho U\left\{c(T) \frac{\partial T}{\partial z}+\frac{\partial H_{L}}{\partial z}\right\}=\nabla \cdot(k(T) \nabla T),
$$

where now $\nabla$ denotes the two-dimensional $(x, y)$ del-operator. During the casting process, heat flows from the liquid steel across the layers of solid steel, liquid flux and solid flux into the surrounding mould, from which the heat is removed by the cooling water. The heat transfer from the surrounding mould to the cooling water is assumed to take place by convection. Hence the surface boundary condition can be expressed as,

$$
-k(T)(\partial T / \partial n)=h_{\infty}\left(T-T_{\infty}\right),
$$

where $T_{\infty}$ and $h_{\infty}$ denote respectively the temperature of the cooling water and the surface heat transfer coefficient between the mould wall and the cooling water. Since we are dealing with casting moulds which have a symmetric rectangular cross-section, the computation region is limited to just one quadrant and thus an additional boundary condition is imposed on the planes of symmetry,

$$
\partial T / \partial n=0,
$$


The temperature for $z=0$ is assumed to be that of the temperature of the incoming molten steel, that is

$$
T(x, y, 0)=T_{0},
$$

where $T_{0}$ is assumed to be a constant. Now, (2.6)-(2.9) may be considered to constitute a two dimensional initial boundary value problem which can be solved by the finite element method to yield the temperature distribution in the mould region during the casting process.

2.2. Weighted residual formulation In order to solve the initial boundary value problem described in the previous sub-section by the finite element method, we have to first convert the partial differential equation (2.6) from a pointwise description to a global integral form. For this purpose, we multiply both sides of (2.6) by an arbitrary function $\phi$, and integrate over the relevant domain $\Omega$, thus

$$
\int_{\Omega} \phi \rho U\left\{c(T) \frac{\partial T}{\partial z}+\frac{\partial H_{L}}{\partial z}\right\} d \Omega=\int_{\Omega} \phi \nabla \cdot(k(T) \nabla T) d \Omega .
$$

Noting that

$$
\phi \nabla \cdot(k(T) \nabla T)=\nabla \cdot(\phi k(T) \nabla T)-k(T) \nabla \phi \cdot \nabla T,
$$

and using the divergence theorem, we can deduce that

$$
\begin{aligned}
\int_{\Omega} \phi U \rho c(T) \frac{\partial T}{\partial z} d \Omega+ & \int_{\Omega} k(T) \nabla \phi \cdot \nabla T d \Omega \\
& =\int_{\Gamma} \phi k(T) \frac{\partial T}{\partial n} d \Gamma-\int_{\Omega} \phi U \rho \frac{\partial H_{L}}{\partial z} d \Omega,
\end{aligned}
$$

which is the integral form of the conservation of heat equation (2.6). Now, substitution of (2.7) and (2.8) into (2.12) produces

$$
\begin{aligned}
\int_{\Omega} \phi U \rho c(T) \frac{\partial T}{\partial z} d \Omega+ & \int_{\Omega} k(T) \nabla \phi \cdot \nabla T d \Omega= \\
& \int_{\Gamma} \phi h_{\infty}\left(T_{\infty}-T\right) d \Gamma-\int_{\Omega} \phi U \rho \frac{\partial H_{L}}{\partial z} d \Omega,
\end{aligned}
$$

which, as an integral equation, is an alternative form of the boundary value problem represented by (2.6)-(2.8). 


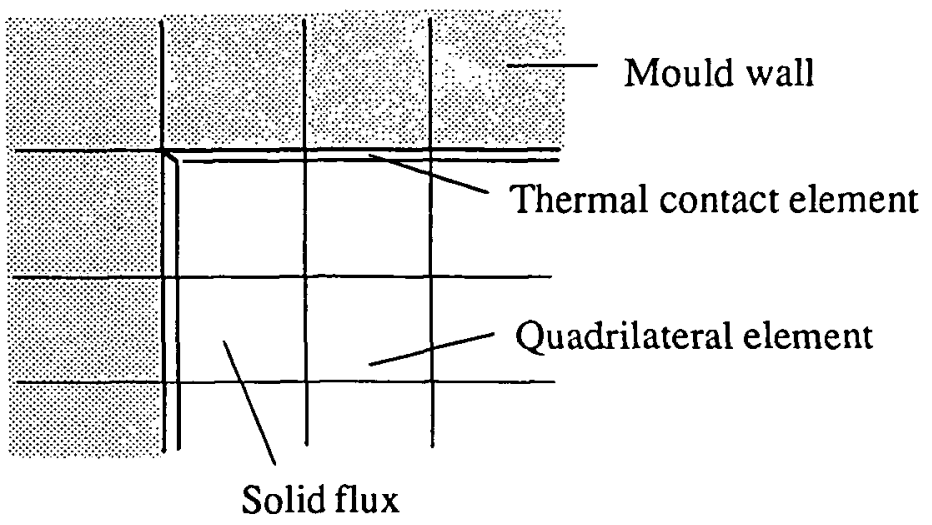

FIGURE 3. Discretized structure for the coupling of the mould wall and the solid flux regions.

\section{Finite element approximation}

3.1. Discretization of space and element interpolation To solve the initial boundary value problem described in the previous section, the domain $\Omega$ is divided into a finite number of simple shaped regions $\Omega_{e}(e=1, E)$ called elements, each having uniform thermal properties. Consequently the boundary $\Gamma$ of the domain $\Omega$ is divided into $N$ segments $\Gamma_{b}(b=1, B)$ called boundary elements. The lubricating layer and the mould wall are connected by the thermal contact elements as shown in Figure 3. Since an Eulerian description of the fluid motion is used in the field equations, these elements are assumed to be fixed in space. Within each element, the coordinate-dependent variables $T$ and $\phi$ are interpolated by functions of compatible order, in terms of values to be determined at a set of nodal points. If we denote $\mathbf{T}_{e}, \mathbf{H}_{\mathrm{Le}}$ and $\phi_{\mathrm{e}}$ as the column vectors of the element nodal point values of $T, H_{L}$ and $\phi$ respectively, and $\mathbf{N}(x, y)$ as the interpolation functions, then the temperature $T$, the latent heat $H_{L}$ and $\phi$ within each element can be expressed as

$$
T(x, y, z)=\mathbf{N}^{T} \mathbf{T}_{\mathbf{e}}(z), \quad H_{L}(x, y, z)=\mathbf{N}^{T} \mathbf{H}_{\mathbf{L}_{\mathbf{e}}}(z), \quad \phi(x, y)=\phi_{\mathbf{e}}^{T} \mathbf{N} .
$$

By applying the weighted residual technique in a single element $\Omega_{e}$, we obtain a corresponding equation to (2.13) with $\Omega$ replaced by $\Omega_{e}$, which on using (3.1) yields

$$
C_{e} \frac{\partial \mathbf{T}_{\mathbf{e}}}{\partial z}+D_{e} \frac{\partial \mathbf{H}_{\mathbf{L}}}{\partial z}+K_{e} \mathbf{T}_{\mathbf{e}}+K_{b} \mathbf{T}_{\mathbf{e}}=\mathbf{f}_{\mathbf{e}}
$$


where $C_{e}, D_{e}, K_{e}, K_{b}$ and $\mathbf{f}_{\mathbf{e}}$ are the element matrices and column vector which are defined by

$$
\begin{aligned}
& C_{e}=\int_{\Omega_{e}} U \rho c(T) \mathbf{N N}^{T} d \Omega, \quad D_{e}=\int_{\Omega_{e}} U \rho \mathbf{N} \mathbf{N}^{T} d \Omega, \\
& K_{e}=\int_{\Omega_{e}} k(T) \nabla \mathbf{N} \cdot \nabla \mathbf{N}^{T} d \Omega, \quad K_{b}=\int_{\Gamma_{b}} h_{\infty} \mathbf{N N}^{T} d \Gamma, \\
& \mathbf{f}_{\mathbf{e}}=\int_{\Gamma_{e}} h_{\infty} \mathbf{N} T_{\infty} d \Gamma
\end{aligned}
$$

The conservation of heat equation for the whole body can be obtained by summing the individual heat conservation equations represented by (3.2) for all elements at the common nodes. By means of this procedure we may obtain the set of simultaneous equations

$$
C \frac{\partial \mathbf{T}}{\partial z}+D \frac{\partial \mathbf{H}_{\mathbf{L}}}{\partial z}+K \mathbf{T}=\mathbf{F},
$$

where $C$ and $K$ are the assembled heat capacity matrix and conductivity matrix respectively, $D$ is an assembled coefficient matrix of the latent heat term, $\mathbf{T}$ and $\mathbf{H}_{L}$ are the temperature and latent heat vectors at all nodes and $\mathbf{F}$ is the external heat source at all nodes. The assembled matrices can be expressed as

$$
C_{i j}=\sum_{e_{i j}} C_{e_{i j}}, \quad D_{i j}=\sum_{e_{i j}} D_{e_{i j}}, \quad K_{i j}=\sum_{e_{i j}} K_{e_{i j}}+\sum_{b_{i j}} K_{b_{i j}}, \quad F_{i}=\sum_{b_{i}} f_{b_{i}},
$$

where $\sum_{e_{i j}}$ denotes summation over all the elements with both nodes $i$ and $j$ and $\sum_{b_{i j}}$ is summation over all the boundary elements with both nodes $i$ and $j$. A detailed description of the element matrices for two dimensional quadrilateral elements will not be described here. The reader is referred to Wu et al. [19] and Zienkiewicz [20] for these details. Here we focus our attention on the derivation of the element matrices for the thermal contact element and the detailed formulation is presented in the following sub-section.

\subsection{Finite element formulation for heat transfer across interface In a com-} posite consisting of two parts, which are brought together as shown in Figure 4, the temperature experiences a sudden drop across the interface. This change in temperature is due to imperfect contact of the two surfaces. Direct contact between the surfaces only takes place at a limited number of points; the voids between them are usually filled with air or the surrounding fluid and heat transfer through these fluid filled voids is mainly by conduction, because there is no 


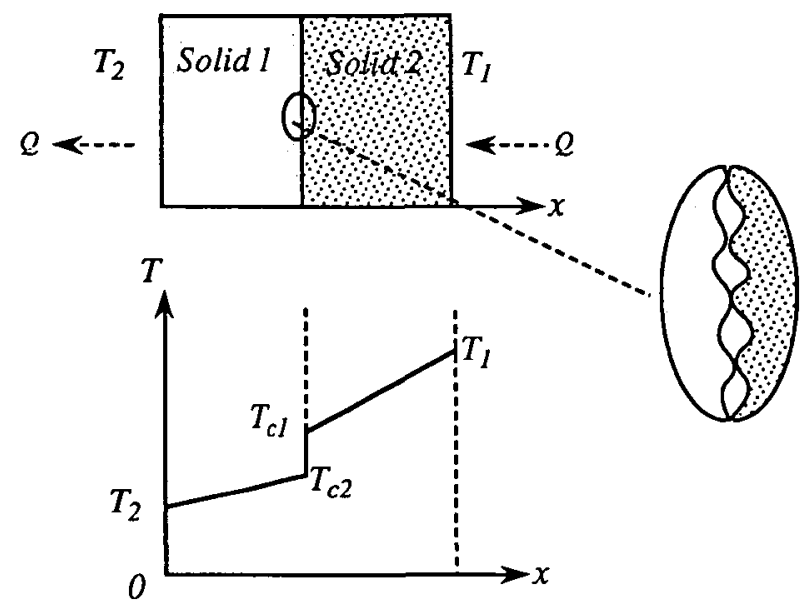

FIGURE 4. Thermal contact resistance.

convection in such thin layers of fluid. Thus, heat transfer across the interface takes place entirely by conduction either through the thin fluid layer filling the voids or directly through the points in solid-to-solid contact. If the thermal conductivity of the fluid or the air is less than that of the solids, then the interface acts as a resistance to heat flow across it; this resistance is referred to as the thermal contact resistance (Ozisik [13]).

In order to simulate the thermal contact resistance in a finite element analysis, we propose a new type of element which we refer to as the thermal contact element and which is shown in Figure 5. The element is one dimensional with zero thickness. Since there is a drop of temperature across the interface, we denote the temperature on one side ( line segment 1-4) as $T^{-}(\xi)$, and on the other side ( line segment 2-3) as $T^{+}(\xi)$. Within each element, the temperature is approximated through the use of the interpolation functions

$$
N_{1}=N_{2}=(1-\xi) / 2, \quad N_{3}=N_{4}=(1+\xi) / 2,
$$

as

$$
T^{-}(\xi)=N_{1}(\xi) T_{1}+N_{4}(\xi) T_{4}, \quad T^{+}(\xi)=N_{2}(\xi) T_{2}+N_{3}(\xi) T_{3} .
$$

Since the heat flux across the interface is proportional to the temperature gradient across the interface and inversely proportional to the thermal contact resistance $R$, we also have

$$
-q_{n}=k \frac{\partial T}{\partial \eta}=\frac{T^{+}(\xi)-T^{-}(\xi)}{R} .
$$




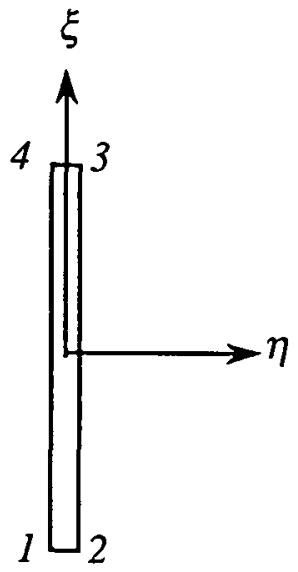

FIGURE 5. A four node thermal contact element.

By applying the weighted residual technique in a single element, we have from (2.12)

$$
\begin{aligned}
\int_{\Omega_{e}} \phi U \rho c(T) \frac{\partial T}{\partial z} d \Omega+ & \int_{\Omega_{e}} k(T) \nabla \phi \cdot \nabla T d \Omega \\
& =w \int_{\Gamma_{e}} \phi k(T) \frac{\partial T}{\partial n} d \Gamma-\int_{\Omega_{e}} \phi U \rho \frac{\partial H_{L}}{\partial z} d \Omega .
\end{aligned}
$$

Since for the thermal contact element $\Omega_{e}=0$ and the functions $\phi, T, H_{L}$ and their derivatives with respect to $z, \xi$ are all continuous, we further have

$$
\int_{\Omega_{e}} \phi U \rho c(T) \frac{\partial T}{\partial z} d \Omega=\int_{\Omega_{e}} \phi U \rho \frac{\partial H_{L}}{\partial z} d \Omega=\int_{\Omega_{e}} \frac{\partial \phi}{\partial \xi} k(T) \frac{\partial T}{\partial \xi} d \Omega=0 .
$$

Thus we can deduce from (3.9) and (3.10) that

$$
\int_{\Omega_{e}} k(T) \frac{\partial \phi}{\partial \eta} \frac{\partial T}{\partial \eta} d \Omega=\int_{\Gamma_{e}} \phi k(T) \frac{\partial T}{\partial n} d \Gamma
$$

so that on using (3.8) we may deduce

$$
\int_{-\frac{1}{2}}^{\frac{1}{2}} \frac{T^{+}(\xi)-T^{-}(\xi)}{R}\left(\phi^{+}-\phi^{-}\right) d \xi=\int_{\Gamma_{e}} \phi k(T) \frac{\partial T}{\partial n} d \Gamma,
$$

where $l$ is the length of the element. Using the same interpolation function for $\phi$, that is

$$
\phi^{-}(\xi)=N_{1}(\xi) \phi_{1}+N_{4}(\xi) \phi_{4}, \quad \phi^{+}(\xi)=N_{2}(\xi) \phi_{2}+N_{3}(\xi) \phi_{3},
$$


we may finally deduce

$$
\left(K_{c}\right)\left(\begin{array}{l}
T_{1} \\
T_{2} \\
T_{3} \\
T_{4}
\end{array}\right)=\left(\begin{array}{l}
F_{1} \\
F_{2} \\
F_{3} \\
F_{4}
\end{array}\right),
$$

where

$$
\begin{gathered}
\left(K_{c}\right)=\frac{l}{6 R}\left(\begin{array}{rrrr}
2 & -2 & -1 & 1 \\
-2 & 2 & 1 & -1 \\
-1 & 1 & 2 & -2 \\
1 & -1 & -2 & 2
\end{array}\right), \\
F_{1}=\int_{0_{-}} N_{1} k \frac{\partial T^{-}}{\partial n} d \Gamma, \quad F_{2}=\int_{0_{+}} N_{2} k \frac{\partial T^{+}}{\partial n} d \Gamma, \\
F_{3}=\int_{0_{+}} N_{3} k \frac{\partial T^{+}}{\partial n} d \Gamma, \quad F_{4}=\int_{0_{-}}^{N_{4} k \frac{\partial T^{-}}{\partial n} d \Gamma .}
\end{gathered}
$$

We note that the matrix $\left(K_{c}\right)$ represents the element conductivity matrix and $F_{i}$ represents the equivalent concentrated heat source entering the element at node $i$.

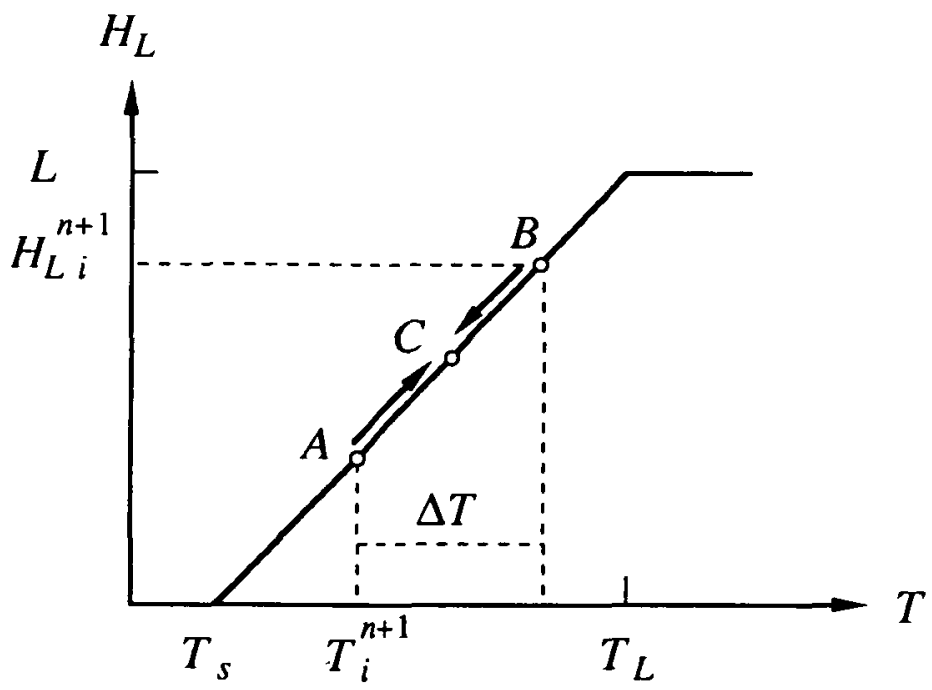

FIGURE 6. Diagram showing the iteration process. 
3.3. Solution procedure Using the backward Euler differentiation scheme, we can deduce from (3.4)

$$
\left(\frac{C}{\Delta z}+K\right) \mathbf{T}^{n+1}=\mathbf{F}^{n+1}+\frac{1}{\Delta z}\left(C \mathbf{T}^{n}+D \mathbf{H}_{\mathbf{L}}^{n}\right)-\frac{D}{\Delta z} \mathbf{H}_{\mathbf{L}}^{n+1},
$$

which constitute a system of nonlinear equations, because in general $C, K$, $\mathrm{F}^{n+1}$ and $\mathbf{H}_{\mathrm{L}}^{n+1}$ all depend on $\mathrm{T}^{n+1}$. In the present analysis $C$ and $K$ are frozen at the values of $\mathbf{T}^{n}$ at the previous time step, while for $\mathbf{H}_{\mathbf{L}}\left(\mathbf{T}^{n+1}\right)$ we have a nonlinearity to deal with. One way of treating this source term for an iterative solution of (3.16) would be to use the iterative update

$$
\begin{gathered}
\left(\mathbf{H}_{L}^{n+1}\right)_{i+1}=f\left(\mathbf{T}_{i}^{n+1}\right), \\
\left(\frac{C}{\Delta z}+K\right) \mathbf{T}_{i+1}^{n+1}=\mathbf{F}_{i}^{n+1}+\frac{1}{\Delta z}\left(C \mathbf{T}^{n}+D \mathbf{H}_{\mathbf{L}}^{n}\right)_{i}-\frac{D}{\Delta z}\left(\mathbf{H}_{\mathbf{L}}^{n+1}\right)_{i+1},
\end{gathered}
$$

where the function $f$ is defined by (2.5) and the subscript $i$ indicates evaluation at the ith iterative step. However, numerical experiments indicate that this iterative scheme is not reliable, especially when the difference between the solidification temperature $T_{s}$ and the liquid temperature $T_{L}$ is small, because during iteration, the temperature $T$ at some points may oscillate between values greater than $T_{L}$ and values less than $T_{s}$ and convergence will not be achieved. To overcome this problem, several alternative schemes have been proposed. Among these schemes, that due to Voller and Prakash [18] is generally recognized as the most efficient scheme. We found that this scheme can be improved by combining it with the relaxation method. The modified iterative scheme used here is as follows

$$
\begin{aligned}
\Theta & =\left(\mathbf{H}_{L}^{n+1}\right)_{i}+\beta c\left\{\mathrm{~T}_{i}^{n+1}-\left(\frac{T_{L}-T_{s}}{L}\left(\mathbf{H}_{L}^{n+1}\right)_{i}+T_{s}\right)\right\}, \\
\left(\mathbf{H}_{L}^{n+1}\right)_{i+1} & =\left\{\begin{array}{cc}
L & \Theta \geq L, \\
\Theta & 0<\Theta<L, \\
0 & \Theta \leq 0,
\end{array}\right.
\end{aligned}
$$

where $\beta(\beta<1)$ is a relaxation factor and $c$ is the specific heat. The iteration process is shown in Figure 6 and a possible mechanism for the determination of $\beta$ is as follows. We consider the solution corresponding to the ith iteration cycle and if the temperature and latent heat at a particular material point fall at different points $A$ and $B$ in the $H_{L}-T$ curve, then in the (i+1)th iteration cycle, 
the latent heat released is forced to be an amount such that the temperature at the point increases by $\beta \nabla T$ and both points $A$ and $B$ move to a new point $C$. Thus from consideration of heat conservation, we have

$$
\beta \Delta T c=\frac{(1-\beta) \Delta T}{T_{L}-T_{s}} L
$$

which leads to

$$
\beta=\left(1+\frac{c}{L}\left(T_{L}-T_{s}\right)\right)^{-1} .
$$

Here we remark that Voller and Prakash's iterative scheme corresponds to (3.18) with $\beta=1$.

\section{Numerical investigation of the effect of casting parameters}

4.1. Basic parameters and computation schemes Based on the model presented, a computer program has been developed for the calculation of the temperature field in the mould region. Using the program, a numerical investigation has been conducted to analyse the effect of varying several system parameters (the casting speed, the thermal contact resistance across the interface of the mould wall and the mould flux and the thermal conductivity of the mould powder) on the solidification of steel in the casting mould. The example under consideration is the B.H.P. Newcastle Bloomcaster, with a mould width of $632 \mathrm{~mm}$, a breadth of $402 \mathrm{~mm}$ and a depth of $800 \mathrm{~mm}$. Since the mould is symmetrical about two planes which pass through the central line of the mould and are parallel to the broad and narrow faces of the mould respectively, the computation region is limited to just one quadrant. The temperature in the other parts of the mould region can be obtained from the solution in the computation region. Figure 7 shows the computation region and the grid mesh referred to the coordinate system adopted. The thickness of the flux layer is assumed to be $2 \mathrm{~mm}$ and the mesh is designed in such a way that each element contains only one kind of material. The regions of the lubricating layer and the mould wall are connected by the thermal contact element as mentioned in Section 3 . The heat transfer from the surrounding copper mould to the cooling water which passes through the channels in the mould is assumed to take place by convection with a constant heat transfer coefficient $h_{\infty}=10000 \mathrm{~W} / \mathrm{m}^{2 \circ} \mathrm{C}$.

In this study, seven computation schemes are designed to investigate the effect of the casting speed $U$, the thermal contact resistance $R$ and the thermal 


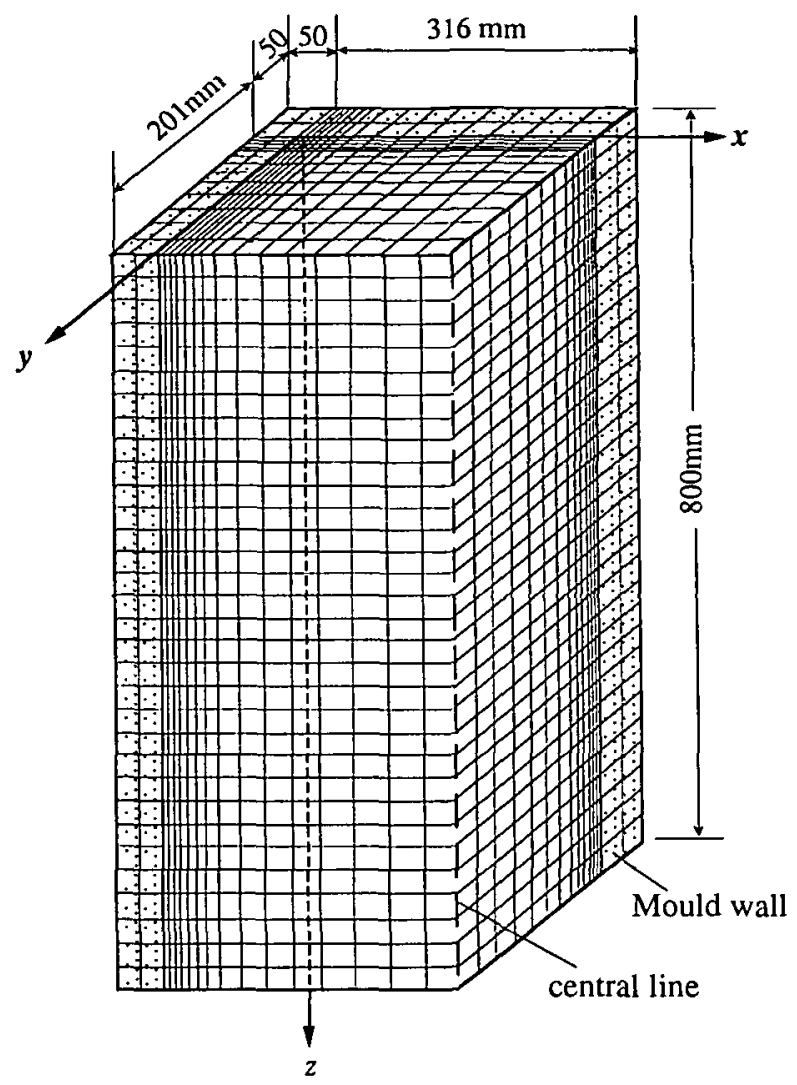

FIGURE 7. Coordinate system, computation region and the grid mesh.

conductivity $k$ of the mould powder on the solidification of steel in the mould region during the continuous casting process. All the parameters to be employed in the computation for different schemes are kept the same except the casting speed, the thermal contact resistance and the thermal conductivity of the mould powder. In general, the thermal contact resistance $\mathbf{R}$ and the thermal conductivity $k$ of the mould powder are functions of the temperature. However for simplicity, we consider the case in which both $R$ and $k$ are temperature independent. According to the experimental results by Mills et al. [11], Ohmiya et al. [12] and Taylor and Mills [16], the thermal contact resistance $R$ is taken to be within the range of $1-3 \times 10^{-4} \mathrm{~m}^{2 \circ} \mathrm{C} / \mathrm{W}$, and the thermal conductivity of the mould powder is taken to be in the range of $0.5-1.5 \mathrm{~W} / \mathrm{m}^{\circ} \mathrm{C}$. The numerical values of all parameters used in the computation were either provided by the B.H.P. 


\begin{tabular}{||c||c|c|c|c|c|c|c|c|c|c||}
\hline \multicolumn{7}{||c||}{} & \multicolumn{9}{|c|}{ Mould powder } & Mould & $\begin{array}{c}\text { Casting } \\
\text { Speed }\end{array}$ & $\begin{array}{c}\text { Thermal } \\
\text { Contact } \\
\text { resistance } \\
R\end{array}$ & $\begin{array}{c}\text { Heat } \\
\text { transfer } \\
\text { coefficient } \\
h_{\infty} \\
\end{array}$ & $\begin{array}{c}c \\
\mathrm{~kg} / \mathrm{m}^{3}\end{array}$ & $\begin{array}{c}c \\
\mathrm{~J} / \mathrm{kg}^{\circ} \mathrm{C}\end{array}$ & $\begin{array}{c}k \\
\mathrm{~W} / \mathrm{m}^{\circ} \mathrm{C}\end{array}$ & $\begin{array}{c}T_{s} \\
{ }^{\circ} \mathrm{c}\end{array}$ & $\begin{array}{c}T_{L} \\
{ }^{\circ} \mathrm{C}\end{array}$ & $\begin{array}{c}L \\
\mathrm{~J} / \mathrm{g}\end{array}$ & $\begin{array}{c}k \\
\mathrm{~W} / \mathrm{m}^{\circ} \mathrm{C}\end{array}$ & $\begin{array}{c}U \\
\mathrm{~m} / \mathrm{min}\end{array}$ & $\mathrm{m}^{2 \circ} \mathrm{C} / \mathrm{W}$ & $\mathrm{W} / \mathrm{m}^{2 \circ} \mathrm{C}$ \\
\hline \hline 1 & 2930 & 1000 & 1.0 & 1000 & 1250 & 428 & 200 & 0.75 & 0.0002 & 10000 \\
\hline 2 & 2930 & 1000 & 1.0 & 1000 & 1250 & 428 & 200 & 1.00 & 0.0002 & 10000 \\
\hline 3 & 2930 & 1000 & 1.0 & 1000 & 1250 & 428 & 200 & 0.50 & 0.0002 & 10000 \\
\hline 4 & 2930 & 1000 & 1.0 & 1000 & 1250 & 428 & 200 & 0.75 & 0.0001 & 10000 \\
\hline 5 & 2930 & 1000 & 1.0 & 1000 & 1250 & 428 & 200 & 0.75 & 0.0003 & 10000 \\
\hline 6 & 2930 & 1000 & 0.5 & 1000 & 1250 & 428 & 200 & 0.75 & 0.0002 & 10000 \\
\hline 7 & 2930 & 1000 & 1.5 & 1000 & 1250 & 428 & 200 & 0.75 & 0.0002 & 10000 \\
\hline
\end{tabular}

\begin{tabular}{||c||c|c|c|c|c|c||}
\hline \multicolumn{1}{||||}{} & \multicolumn{7}{c||}{ Steel } \\
\cline { 2 - 7 } & $\begin{array}{c}\rho \\
\mathrm{kg} / \mathrm{m}^{3}\end{array}$ & $\begin{array}{c}c \\
\mathrm{~J} / \mathrm{kg}^{\circ} \mathrm{C}\end{array}$ & $\begin{array}{c}k \\
\mathrm{~W} / \mathrm{m}^{\circ} \mathrm{C}\end{array}$ & $\begin{array}{c}T_{s} \\
{ }^{\circ} \mathrm{C}\end{array}$ & $\begin{array}{c}T_{L} \\
{ }^{\circ} \mathrm{C}\end{array}$ & $\begin{array}{c}L \\
\mathrm{~J} / \mathrm{g}\end{array}$ \\
\hline \hline 1 & 7800 & 465 & 35 & 1465 & 1525 & 272 \\
\hline 2 & 7800 & 465 & 35 & 1465 & 1525 & 272 \\
\hline 3 & 7800 & 465 & 35 & 1465 & 1525 & 272 \\
\hline 4 & 7800 & 465 & 35 & 1465 & 1525 & 272 \\
\hline 5 & 7800 & 465 & 35 & 1465 & 1525 & 272 \\
\hline 6 & 7800 & 465 & 35 & 1465 & 1525 & 272 \\
\hline 7 & 7800 & 465 & 35 & 1465 & 1525 & 272 \\
\hline
\end{tabular}

TABLE 1. Computation schemes

Research, Newcastle Laboratories or determined from the experimental results presented by Ohmiya et al. [10] and are summarized in Table 1.

4.2. Some essential features of temperature profile in mould region All the temperature values at every grid point ( shown in Figure 7 ) under seven different schemes have been computed. However, in order to keep the details to a 


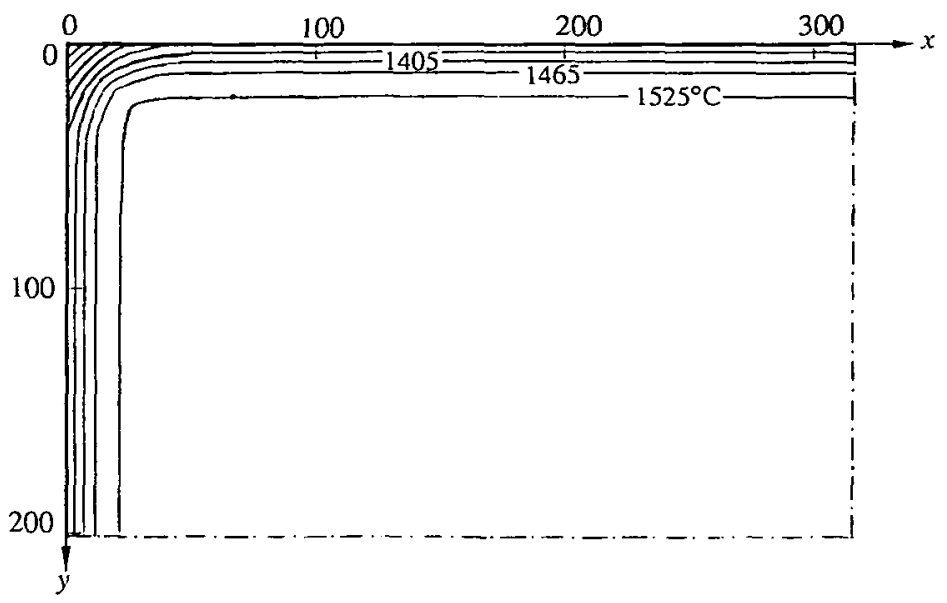

FIGURE 8. Temperature contours on a horizontal plane $(z=800 \mathrm{~mm})$.

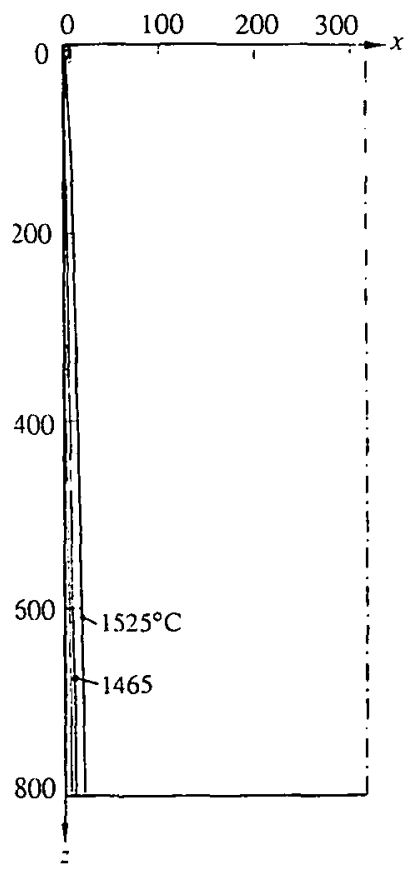

FIGURE 9. Temperature contours on the central vertical planes parallel to the broad face of the mould wall ( $y=201 \mathrm{~mm})$. 
minimum we only present a selection of the computed results for scheme 1 , which may be helpful for understanding the general features of heat transfer in the mould region.

Figure 8 shows the temperature contours on a horizontal cross section. From this figure, the solidified steel region and the mushy region can be located. The solidified region is the area in which the temperature of steel is below the solidification temperature $\left(1465^{\circ} \mathrm{C}\right)$ and the mushy region is the area in which the temperature of steel lies between the solidification temperature and the melting point $\left(1465^{\circ} \mathrm{C}-1525^{\circ} \mathrm{C}\right)$. We note that the thickness of the solidified steel shell on the presented horizontal cross-sections is almost uniform along the mould walls.

Figure 9 shows the temperature contours on the central vertical plane parallel to the broad faces of the mould wall. It is indicated that both the interface between the solidified region and the mushy region and the interface between the mushy region and the liquid region are the nonlinear functions of the depth down the meniscus of the molten steel. The gradients of the interfaces with respect to the depth decrease with the depth, which means that the solidification speed decreases with depth.

Figure 10 shows the distribution of temperature from the mould wall towards the central line of the mould along various $x$-parallel lines. It is apparent that there is a significant drop of temperature across the interface between the mould wall and the mould flux. This sudden drop of temperature is due to the thermal contact resistance between the mould wall and the mould flux. It is also apparent that the gradient of temperature in the region of mould flux is much higher than that in the steel region, which is because the thermal conductivity of mould powder is much lower than that of the steel.

4.3. Effect of casting speed The casting speed was varied from $0.5 \mathrm{~m} / \mathrm{min}$ to $1 \mathrm{~m} / \mathrm{min}$ in schemes 1 to 3 , to investigate the effect of casting speed on the solidification of steel. Figure 11 shows the variations of temperature along a $y$-parallel line ( $x=316 \mathrm{~mm}, z=800 \mathrm{~mm})$ under different schemes. It can be noted that within about $27 \mathrm{~mm}$ from the strand surface, the temperature of the steel increases with increasing casting speed.

Figure 12 shows the heat extraction rate from the mould wall and the heat removed by the cooling water from a unit volume of molten steel which passes through the mould from the top to the bottom. The rate of heat extraction from the mould wall increases with increasing casting speed. However the heat removed from a unit volume of molten steel decreases with increasing casting 


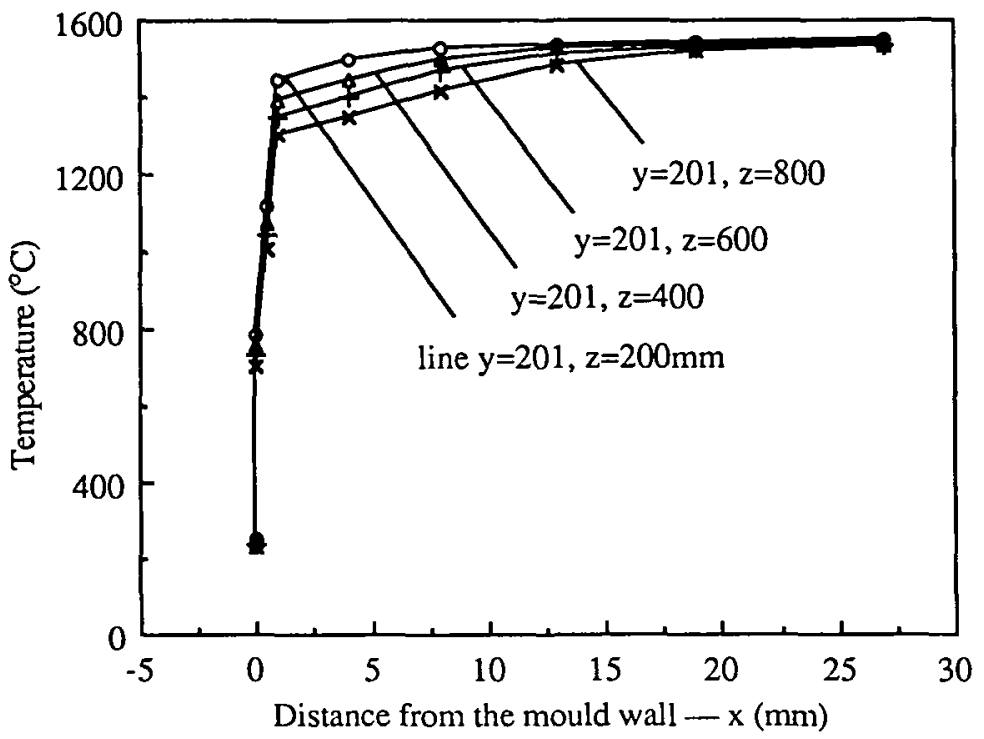

FIGURE 10. Distributions of temperature along various $x$-parallel lines.

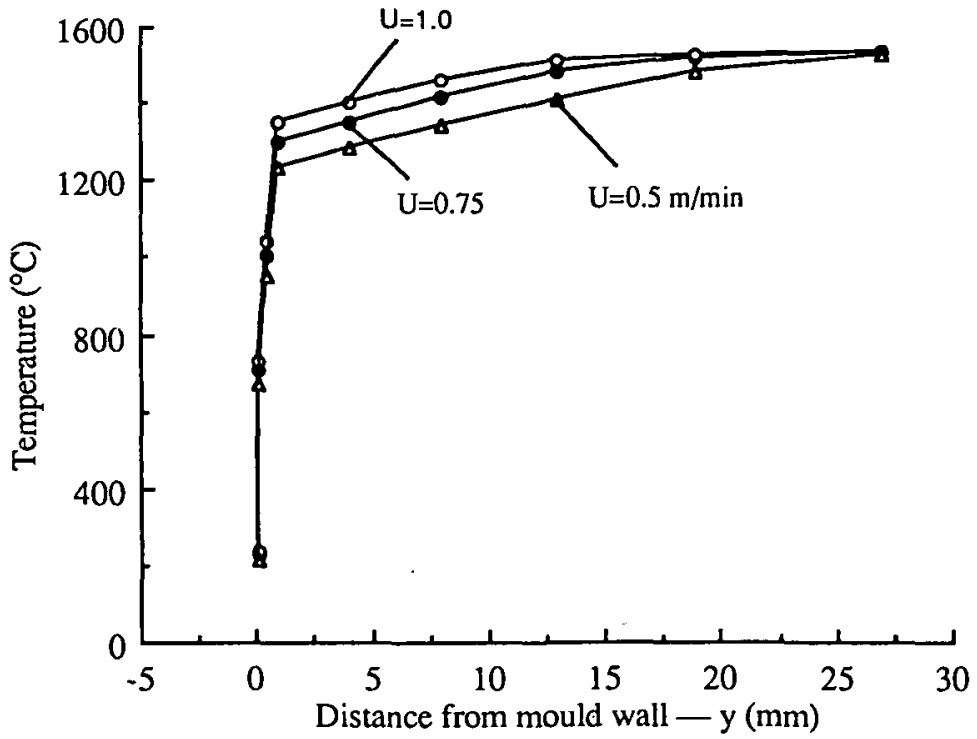

FIGURE 11. Effect of casting speed $U$ of the steel on the temperature profile in line $(x=316 \mathrm{~mm}$, $z=800 \mathrm{~mm}$ ). 


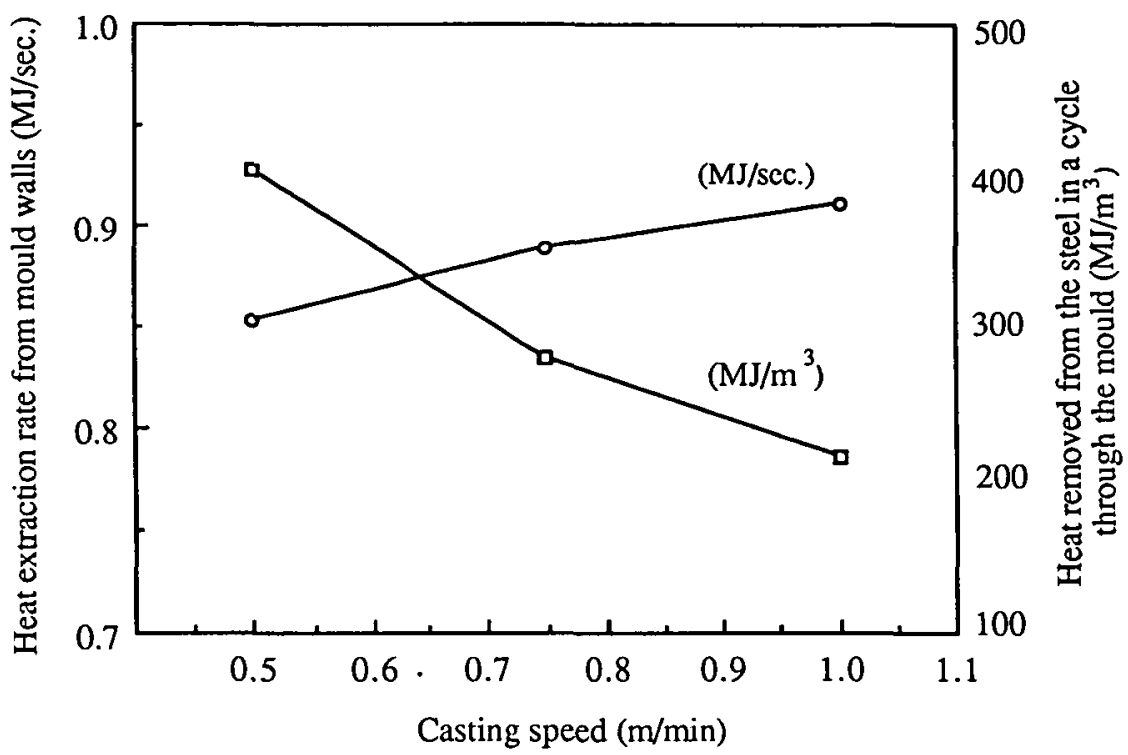

FIGURE 12. Effect of casting speed $U$ of the steel on the overall heat extraction rate from the mould wall.

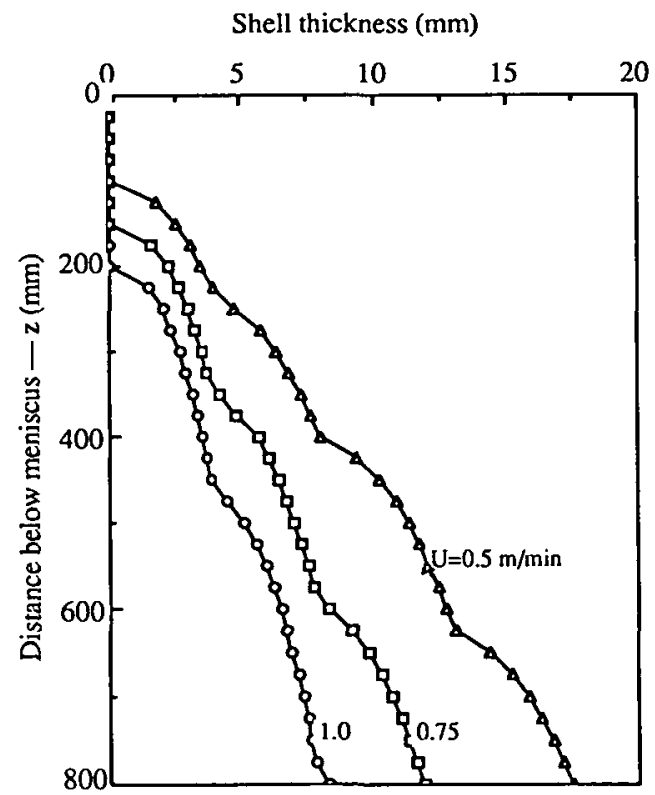

FIGURE 13. Effect of casting speed $U$ of the steel on the shell thickness on plane $x=316 \mathrm{~mm}$. 


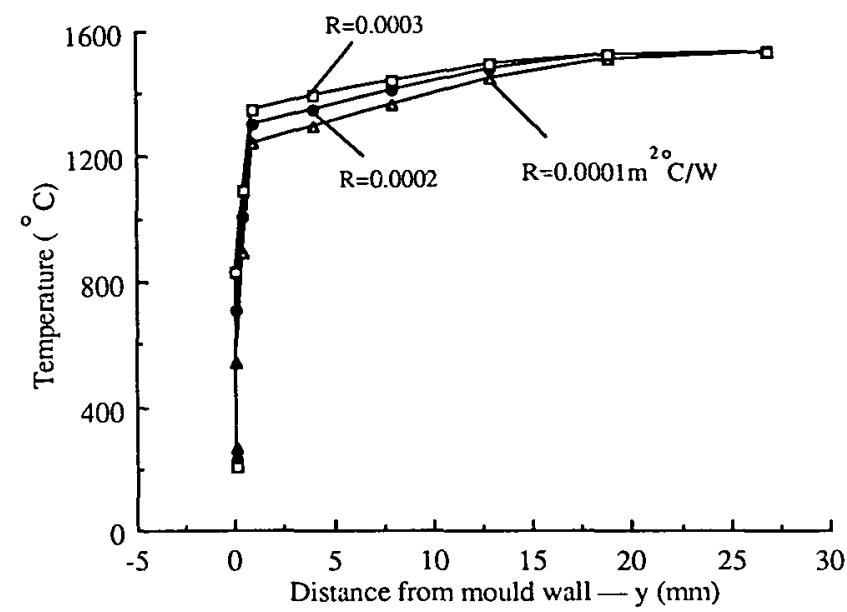

FIGURE 14. Effect of thermal contact resistance $R$ on the temperature profile in line $(x=316 \mathrm{~mm}$, $z=800 \mathrm{~mm}$ ).

speed and consequently, the thickness of the solidified steel shell decreases as well, which is apparent from Figure 13.

4.4. Effect of thermal contact resistance The effect of thermal contact resistance on the solidification of steel in the continuous casting process is analysed in schemes 1, 4 and 5. The computed temperature profiles, the heat extraction rates and the thickness of the solidified steel shells for different values of thermal contact resistance are compared in Figures 14, 15 and 16 respectively. From Figures 15 and 16 it can be seen that with the decrease of thermal contact resistance from 0.0003 to $0.0002 \mathrm{~m}^{2 \circ} \mathrm{C} / \mathrm{W}$, the heat extraction rate increases by about $15 \%$ and the thickness of the solidified steel shell at the bottom of the mould increases by about $17 \%$.

4.5. Effect of thermal conductivity of mould powder In schemes 1,6 and 7 the thermal conductivity of the mould powder is varied from $0.5 \mathrm{~W} / \mathrm{m}^{\circ} \mathrm{C}$ to $1.5 \mathrm{~W} / \mathrm{m}^{\circ} \mathrm{C}$ to investigate the effect on the solidification of steel in the casting process. The computed temperature profiles, the heat extraction rates and the thickness of the solidified steel shells for different values of thermal conductivity are compared in Figures 17, 18 and 19 respectively. This comparison indicates that the thermal conductivity of mould powders is also an important factor dominating the heat transfer from the molten steel to the cooling water. For example, with the increase of the thermal conductivity value from $1 \mathrm{~W} / \mathrm{m}^{\circ} \mathrm{C}$ to 


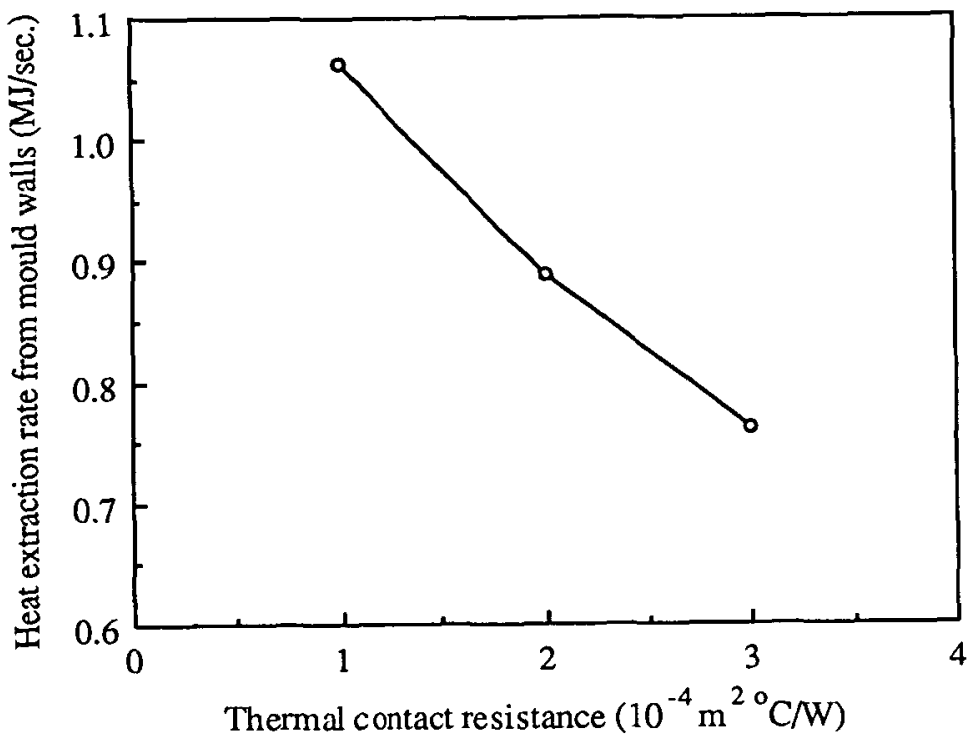

FIGURE 15. Effect of thermal contact resistance $R$ on the overall heat extraction rate from the mould wall.

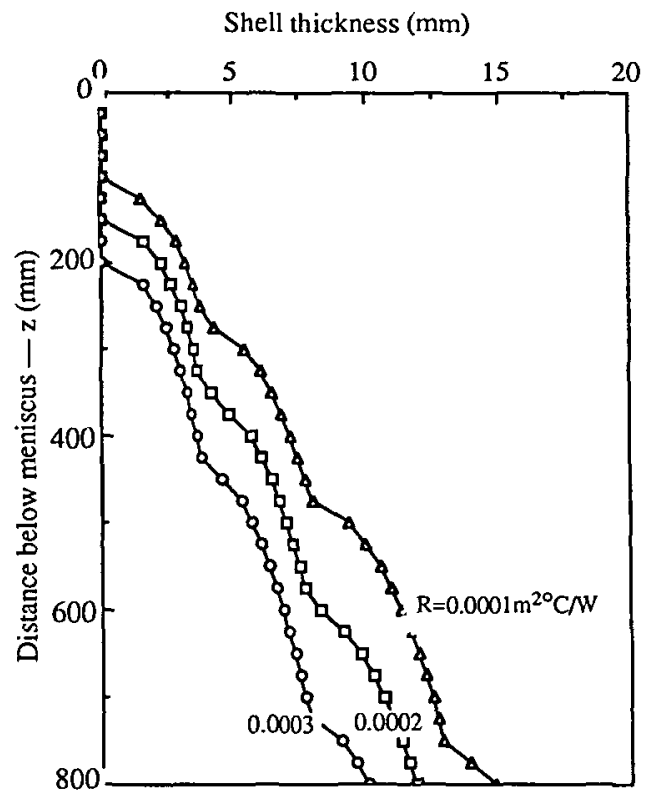

FIGURE 16. Effect of thermal contact resistance $R$ on the shell thickness on plane $x=316 \mathrm{~mm}$. 


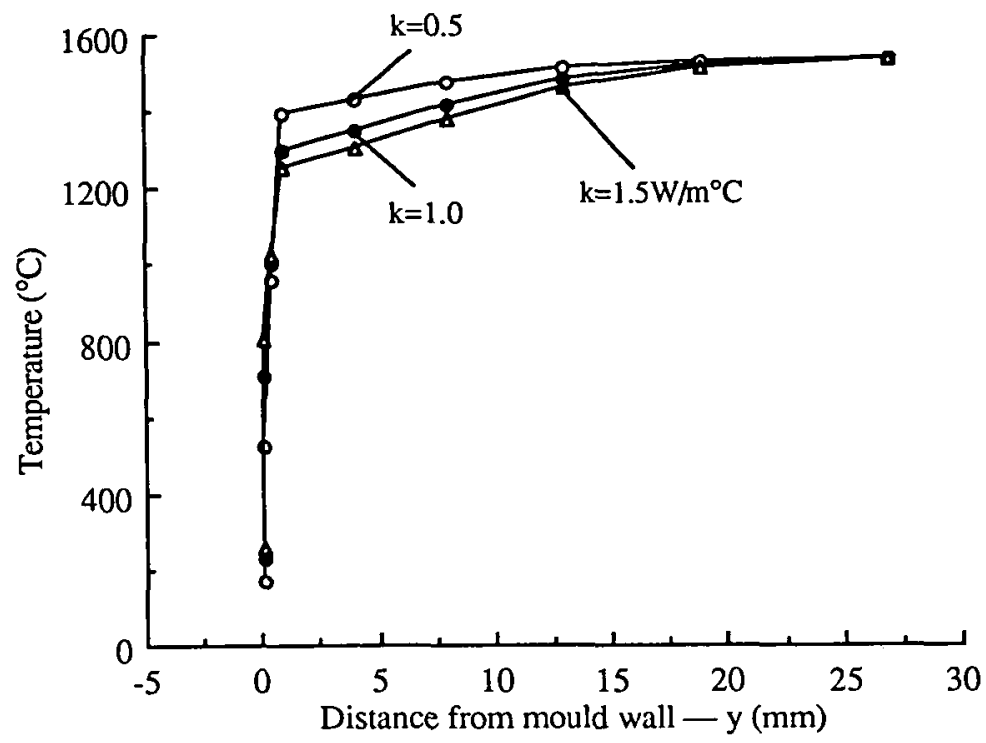

FIGURE 17. Effect of thermal conductivity $k$ of the mould powder on the temperature profile in line $(x=316 \mathrm{~mm}, z=800 \mathrm{~mm})$.

$1.5 \mathrm{~W} / \mathrm{m}^{\circ} \mathrm{C}$ the thickness of the solidified steel shell at the bottom of the mould increases by about $16.5 \%$.

\section{Conclusion}

A new type of finite element, which we refer to as the thermal contact element, has been proposed to simulate the thermal contact resistance across the interface between two bodies and a numerical model, which incorporates this new type of element, has been developed to simulate the multiphase heat transfer during solidification in the continuous casting of steel. This model has been used to calculate the temperature field and consequently to locate the solidified region of the steel in the mould under different operating conditions. Therefore the model provides a good basis for the design of the casting system.

Our parametric study has shown that heat transfer in the continuous casting mould is very complicated. All the parameters such as the casting speed, the thermal contact resistance and the thermal conductivity of the mould powder have a considerable effect on heat transfer and solidification of steel in the mould. In the continuous casting process, the thickness of the solidified steel shell at the 


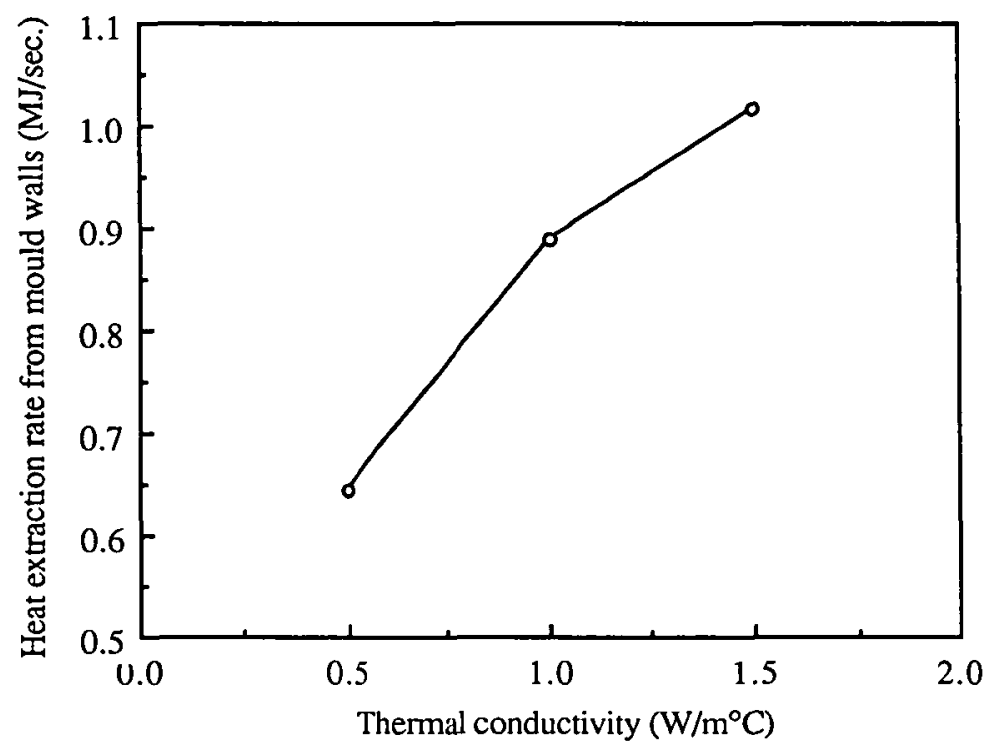

FIGURE 18. Effect of thermal conductivity $k$ of the mould powder on the overall heat extraction rate from the mould wall.

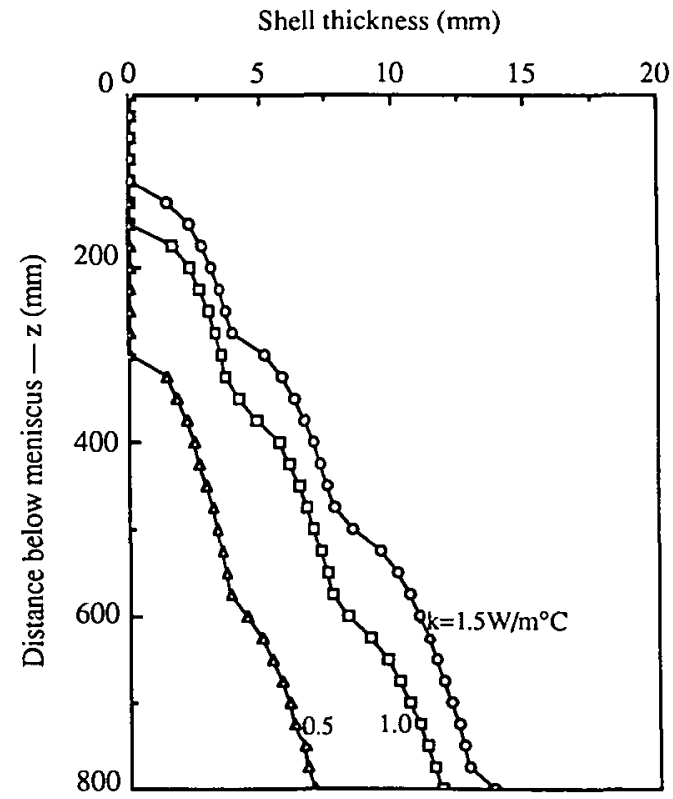

FIGURE 19. Effect of thermal conductivity $k$ of the mould powder on the shell thickness on plane $x=316 \mathrm{~mm}$. 
bottom of the mould is critical to the smooth operation of the process, because a shell which is too thin may result in breakout of molten steel from the bottom of the mould while a shell which is too thick may lead to the formation of cracks at the bending rolls. Our study has shown that the thickness of the solidified steel shell at the bottom of the mould decreases with increasing casting speed but increases with a decrease of the thermal contact resistance and an increase of the thermal conductivity of the mould powder. Thus in practice, there are various options of choosing the casting operating system in order to obtain an expected thickness of the solidified steel shell and an expected heat extraction rate. For example, for a particular casting system, if the casting speed is to be increased, the same heat extraction rate or the thickness of the solidified steel shell can still be obtained by decreasing the thermal contact resistance between the mould wall and the mould flux or by increasing the thermal conductivity of the mould powder used.

\section{Acknowledgement}

The first author gratefully acknowledges the financial support of an Australian Research Council Post-doctoral Fellowship. The authors are grateful to the referees whose comments have materially improved the presentation.

\section{References}

[1] D. R. Bland, "Flux and the continuous casting of steel", IMA J. of Appl. Math. 32 (1984) 89-112.

[2] J. K. Brimacombe, I. V. Samarasekera and J. E. Laid (eds.), Continuous casting, Vol. 2 Heat flow, solidification and crack formation (Iron and Steel Society, AIME, 1983).

[3] P. J. Flint, "A three dimensional finite difference model of heat transfer, fluid flow and solidification in the continuous slab caster", Proc. 73rd ISS steelmaking Conf., Detroit MI, March 25-28 (1990).

[4] N. Fowkes and A. Woods, "The flux of flux in a continuous steel caster", Department of Mathematics Research Report, University of Western Australia (1989).

[5] A. Garcia, M. D. Medeiros and M. Prates de Campos Filho, "Mathematical analysis of thermal behaviour of metal/mould systems during unidirectional solidification", Proc. of the Int. Conf. on Solidification Technology in the Foundry and Casthouse, Metals Society, London (1983) 27-32.

[6] J. J. Gautier, Y. Morillon and J. Dumont-Fillon, "Mathematical study of the continuous casting of steel", Procs. of the Conference on Mathematical Models in Metallurgical Development, The Iron and Steel Institute, London (1969) 178-185. 
[7] A. Grill, K. Sorimachi and J. K. Brimacombe, "Heat flow, gap formation and break-outs in the continuous casting of steel slabs", Met. Trans. B7 (1976) 177-189.

[8] C. P. Hong, T. Umeda and T. Kimura, "Numerical models for casting solidification: Part 1, the coupling of the boundary element and finite difference methods for solidification problems; Part 2, application of the boundary element method to solidification problems", Metallurgical Transactions B 15 (1984) 91-107.

[9] J. E. Lait, J. K. Brimacombe and F. Weinberg, "Mathematical modelling of heat flow in the continuous casting of steel”, Ironmaking and Steelmaking 1 (1974) 90-97.

[10] E. Laitinen and P. Neittaanmaki, "On numerical simulation of the continuous casting process", J. Eng. Math. 22 (1988) 335-354.

[11] K. C. Mills, A. Olusanya, R. Brooks, R. Morrell and S. Bagha, "Physical properties of casting powders: part 4 physical properties relevant to fluid and thermal flow", Ironmaking and Steelmaking 15 (1988) 257-264.

[12] S. Ohmiya, K. H. Tacke and K. Schwerdtfeger, "Heat transfer through layers of casting fluxes", Ironmaking and Steelmaking 10 (1983) 24-30.

[13] M. Necati Ozisik (ed.), Heat transfer (McGraw - Hill, New York, 1985).

[14] L. Schmidt and H. Fredriksson, "Formation of macro-segregation and centre-line cracks in continuously cast", Ironmaking and Steelmaking 2 (1975) 61-67.

[15] Toshiyuki Soejima, Minoru Kitamura, Shinji Koyama and Junji Abu, Surface quality of continuous cast slabs at Kobe Steel's Kakogawa Works (Iron and Steel Society, AIME, USA, 1987) 67-73.

[16] R. Taylor and K. C. Mills, "Physical properties of casting powders: part 3 thermal conductivities of casting powders", Ironmaking and Steelmaking 15 (1988) 187-194.

[17] E. A. Upton, T. R. S. Rao, P. H. Dauby and R. C. Knechtges, "Physical metallurgy and mathematical modelling as tools for continuous casting optimization at LTV steel", Ironmaking and Steelmaking 15 (1988) 51-57.

[18] V.R. Voller and C. Prakash, "A fixed grid numerical modelling methodology for convectiondiffusion mushy region phase-change problems", Int. J. Heat and Mass Transfer 30 (1987) 1709-1719.

[19] Y. H. Wu, J. M. Hill and P. J. Flint, "Numerical simulation of heat transfer and solidification in the continuous casting of steel", Department of Mathematics Research Report, The University of Wollongong, NSW 2500, Australia (1991) .

[20] О. C. Zienkiewicz (ed.), The finite element method in engineering science (McGraw P Hill, London, 1979). 